\title{
Growth and Reproduction in the First Two and Summer Generations of Two Citrus Aphids, Aphis citricola van DER GooT and Toxoptera citricidus (KIRKALDY) (Homoptera: Aphididae), under Different Thermal Conditions ${ }^{1}$
}

\author{
Shinkichi KomazaKı \\ Okitsu Branch, Fruit Tree Research Station MAFF, \\ Okitsu, Shimizu, Shizuoka 424-02, Japan
}

(Received July 17, 1987)

\begin{abstract}
Growth and reproduction were compared between Toxoptera citricidus and Aphis citricola. Comparisons were also made among the first generation, which consisted of fundatrices, the second generation, and the subsequent summer generations of each species. In both species, fundatrices developed more slowly than second and subsequent generation individuals. The fastest development took place in the summer generations in T. citricidus and the second generation in A. citricola. Capacity for increase, net reproductive rate and the maximum fecundity were largest in the second generation in both species. The difference in maximum fecundity between the summer generations and the first two generations in A. citricola was less than that of the same category in $T$. citricidus. Net reproductive rate of $T$. citricidus was usually larger than that of $A$. citricola. Reproductive schedule as displayed by the distribution of age specific fecundity changed with temperature and among generations. As for cohort generation time, the second generation was intermediate between the first and summer generations in $T$. citricidus, while in $A$. citricola the first and second generations were nearly the same.
\end{abstract}

\section{INTRODUCTION}

Various morphs that differ in morphology and/or biology are found in aphids. The viviparous female developing from the overwintering egg is called the fundatrix. Fundatrices differ in many morphological respects from the apterous viviparous females of later generations (Hille Ris Lambers, 1966). In addition, there are some reports that fundatrices and their successors, i.e. fundatrigeniae, differed in reproductive potential from parthenogenetic females which appeared in later seasons (TAKAOKA, 1960; Taylor, 1975; Dixon and Dharma, 1980; Leather and Dixon, 1981; Takada, 1984; Leather and Wellings, 1981; Wiktelius and Chiverton, 1985).

In the present study, growth and reproduction of two citrus aphids, Aphis citricola and Toxoptera citricidus, were investigated at various temperatures and comparisons of these features were made among generations and between species. These species are the major aphids which overwinter on citrus trees (Komazaki et al., 1979; Komazaki, 1983; Komazaki et al., 1985) and the collected data will be beneficial in forecasting the

1 Contribution from the Fruit Tree Research Station, B-143 
Table 1. The number of aphids used at respective temperatures tested

\begin{tabular}{|c|c|c|c|c|c|c|c|c|c|}
\hline & \multicolumn{9}{|c|}{ Generation } \\
\hline & \multicolumn{4}{|c|}{ First } & \multicolumn{4}{|c|}{ Second } & Summer ${ }^{a}$ \\
\hline Temperature $\left({ }^{\circ} \mathrm{C}\right)$ & 10.0 & 15.2 & 20.1 & 24.9 & 10.0 & 15.0 & 20.2 & 24.8 & 9.9 \\
\hline No. aphids used & 47 & 42 & 46 & 40 & 48 & 43 & 47 & 50 & 35 \\
\hline \multicolumn{10}{|l|}{ Aphis citricola } \\
\hline Temperature $\left({ }^{\circ} \mathrm{C}\right)$ & 10.6 & 15.0 & 19.5 & 25.1 & 10.0 & 14.9 & 20.0 & 24.9 & 10.1 \\
\hline No. aphids used & 16 & 38 & 43 & 33 & 57 & 52 & 49 & 51 & 42 \\
\hline
\end{tabular}

a Data on other temperatures are described in Komazaki (1982).

spring occurrence of these aphids. In addition, the comparison between species and among generations provides information on the differences in reproductive strategy of these aphids.

\section{MATERIALS AND METHODS}

In the summer of 1979, aphids were collected from a citrus orchard at the Okitsu Branch, Fruit Tree Research Station in Shimizu and reared on potted Citrus unshiu MARK. in net cages. These pots were put in growth cabinets whose temperatures were maintained at $17^{\circ} \mathrm{C}$ (night) and $23^{\circ} \mathrm{C}$ (day) in hot seasons. A. citricola aphids used in experiments were of the citrus biotype (Komazaki, 1986). In fall, the sexual forms (apterous ovipara and alate male) appeared and eggs were deposited on the potted trees in the net cages.

The following spring, fundatrices within one day after eclosion were collected with a fine brush and used for the experiments. The generation of fundatrices is hereafter called the first generation.

For the experiments with individuals of the second generation, fundatrices were reared until maturation and then transferred to new shoots of potted plants in growth cabinets and the newly born nymphs within one day of appearance were used for experiments.

These two generations were reared at temperatures between about $10^{\circ} \mathrm{C}$ to $25^{\circ} \mathrm{C}$, while the subsequent summer generations were reared at about $10^{\circ} \mathrm{C}$, data for temperatures between $15^{\circ}$ and $25^{\circ} \mathrm{C}$ being cited from Komazaki (1982). Experiments on summer generations were carried out during the summer season (from July to September), without regard to any particular generation.

All experiments were done during 1980 to 1985 . The number of aphids used at respective temperatures is listed in Table 1. Aphid maturation and larviposition were observed daily. The pre-reproductive period (from birth to reproduction), longevity, total fecundity per female, age specific survival rates $\left(l_{x}\right)$ and age specific fecundities $\left(m_{x}\right)$ were calculated. For comparison of reproductive capacity among the first, second, and summer generations, the net reproductive rate $\left(R_{0}\right)$, cohort generation time $\left(T_{\mathrm{c}}\right)$, and capacity for increase $\left(r_{\mathrm{c}}\right)$ (LAUGHLIN, 1965) were estimated instead of the

\footnotetext{
${ }^{2}$ Calculations were done by the computer at the Computing Center for Research in the Ministry of Agriculture, Forestry and Fisheries.
} 
innate capacity for increase $\left(r_{m}\right)$ and mean generation time $(T)$, because stable age distribution was not realized in the early generations. The equations are $R_{0}=\sum l_{x} m_{x}$, $r_{\mathrm{c}}=\ln \left(R_{0} / T_{\mathrm{c}}\right)$, and $T_{\mathrm{c}}=\sum x l_{x} m_{x} / \sum l_{x} m_{x}$.

\section{RESULTS}

The pre-reproductive periods at different temperatures and the regression lines of

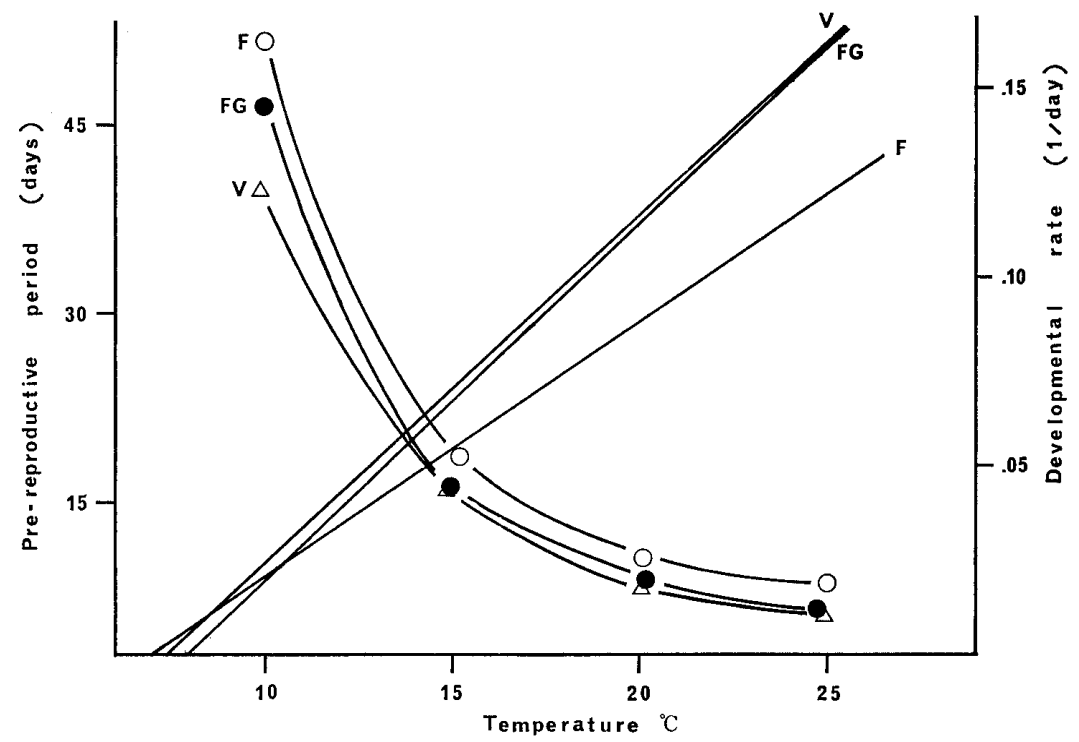

Fig. 1. Pre-reproductive period and developmental rate in Toxoptera citricidus at different temperatures. Straight lines show regression of developmental rate with temperature. F: fundatrices, FG: second generation individuals, V: summer generation individuals.

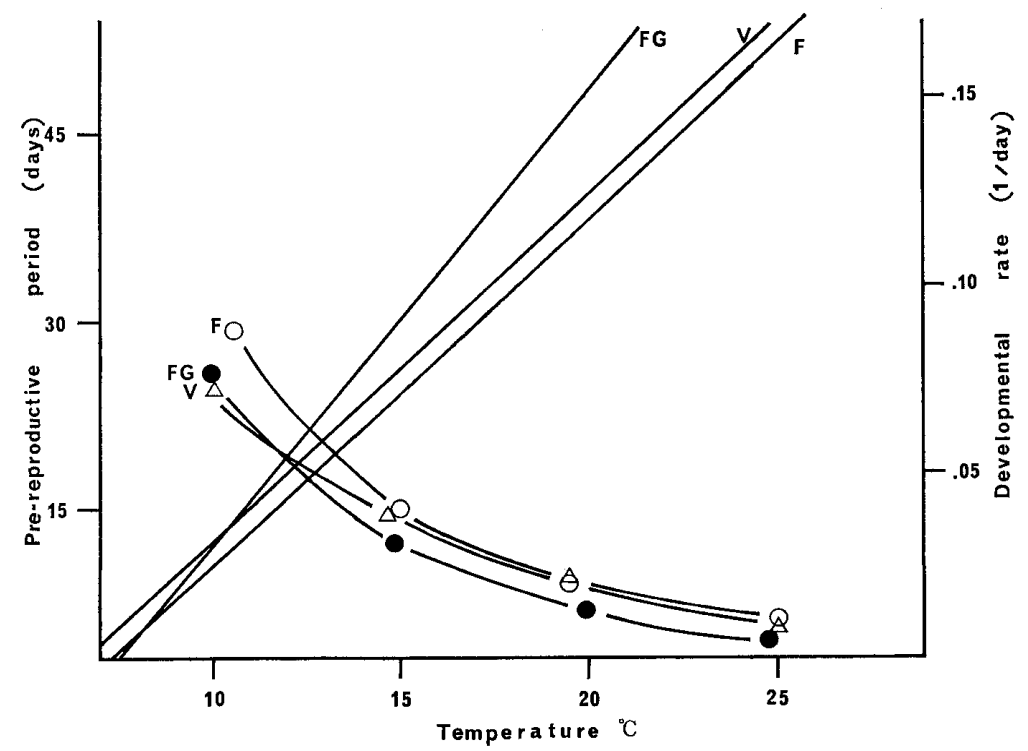

Fig. 2. Pre-reproductive period and developmental rate in Aphis citricola at different temperatures. Straight lines show regression of developmental rate with temperature. F: fundatrices, FG: second generation individuals, $\mathrm{V}$ : summer generation individuals. 
Table 2. Threshold temperatures for development and thermal constants in the respective generations of the two aphid species

\begin{tabular}{|c|c|c|c|}
\hline & \multicolumn{3}{|c|}{ Generation } \\
\hline & First & Second & Summer \\
\hline \multicolumn{4}{|l|}{ Toxoptera citricidus } \\
\hline Threshold temperature $\left({ }^{\circ} \mathrm{C}\right)$ & 6.9 & 7.9 & 7.4 \\
\hline Thermal constant (Day $\left.{ }^{\circ} \mathrm{C}\right)$ & 149.3 & 106.4 & 108.7 \\
\hline \multicolumn{4}{|l|}{ Aphis citricola } \\
\hline Threshold temperature $\left({ }^{\circ} \mathrm{C}\right)$ & 7.3 & 7.7 & 6.7 \\
\hline Thermal constant (Day ${ }^{\circ} \mathrm{C}$ ) & 108.0 & 80.6 & 109.1 \\
\hline
\end{tabular}

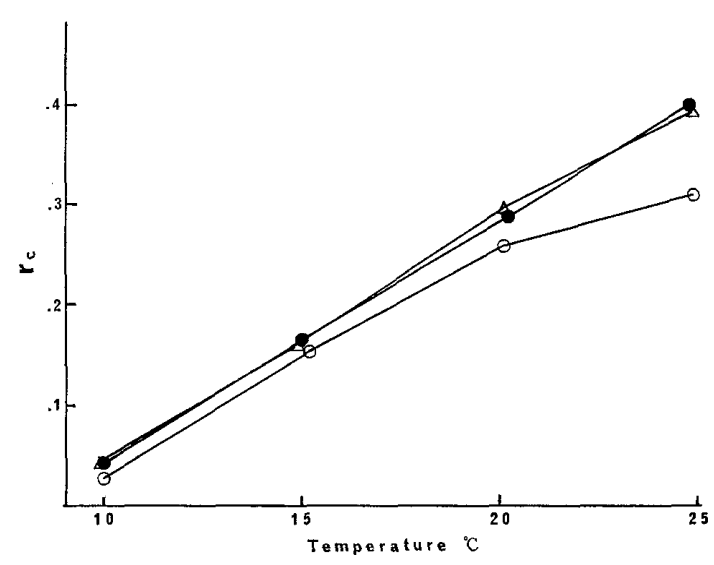

Fig. 3. Relationship between temperature and capacity for increase $\left(r_{\mathrm{c}}\right)$ in Toxoptera citricidus. $O$, and $\Delta$ represent the first (fundatrix), second and the summer generations, respectively.

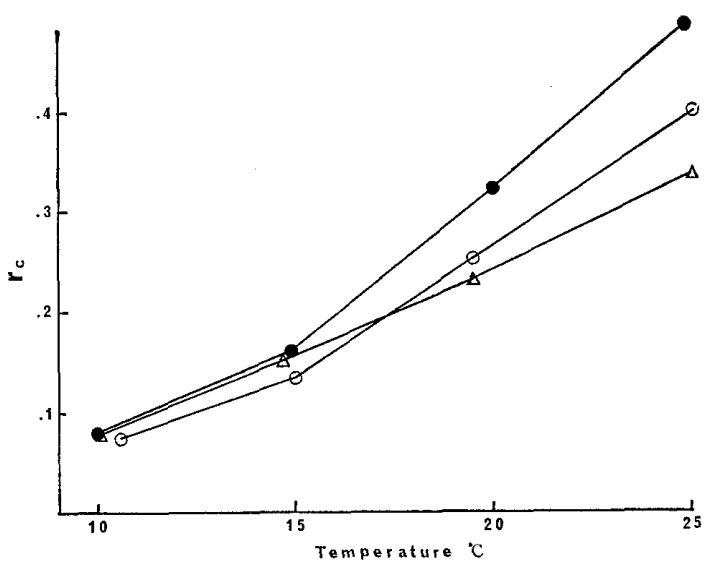

Fig. 4. Relationship between temperature and capacity for increase $\left(r_{\mathrm{c}}\right)$ in Aphis citricola. $\mathrm{O}$, - and $\Delta$ represent the first, second and the summer generations, respectively.

developmental rate with temperature are illustrated in Fig. 1 (T. citricidus) and Fig. 2 (A. citricola). In $T$. citricidus, the development was fastest in the summer generation and slowest in the first one at all temperatures. Second generation individuals required nearly the same time to mature as summer generation ones, except at $10^{\circ} \mathrm{C}$. In $A$. citricola, development of fundatrices was slowest, as was also true in T. citricidus. The quickest development took place in the summer generation in $T$. citricidus but in the second generation in $A$. citricola.

The threshold temperatures for development and thermal constants during the pre-reproductive period were estimated from the regression lines and given in Table 2. The thermal constant was somewhat larger in the first generation for $T$. citricidus, and smaller in the second generation for $A$. citricola than the other generations. In the first and second generations, the thermal constants of $A$. citricola were smaller than those of T. citricidus.

Figures 3 and 4 give relationships between temperature and $r_{\mathrm{c}}$ for the respective species. In $T$. citricidus, there is no difference between the second and summer generations, while all points in the first generation are lower than in the other two. In $A$. citricola, $r_{\mathrm{c}}$ values for the second generation are distinctly high at $20^{\circ} \mathrm{C}$ and $25^{\circ} \mathrm{C}$ as compared with those for the other generations. 


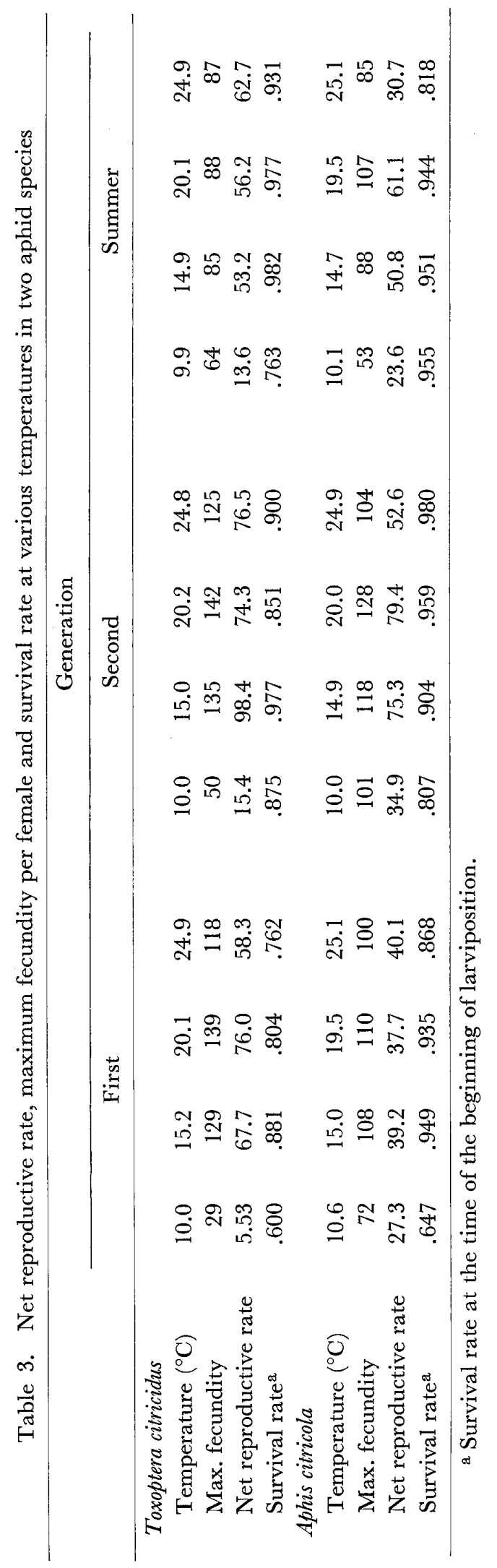




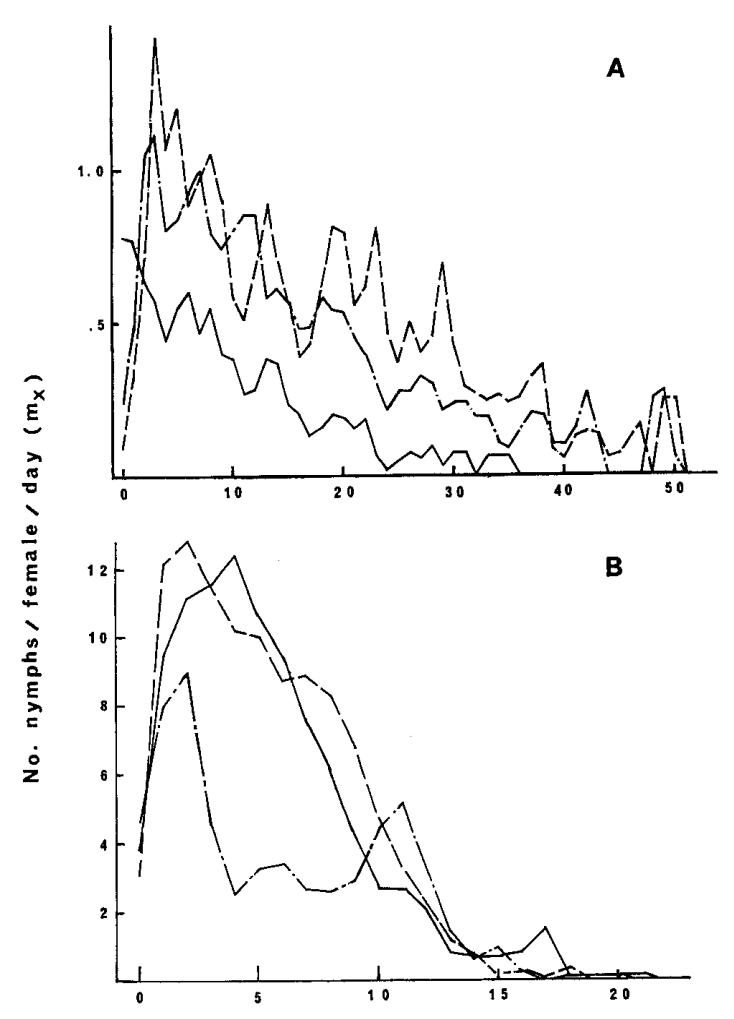

Days after initial reproduction

Fig. 5. Age specific fecundity in Toxoptera citricidus at $10^{\circ} \mathrm{C}(\mathrm{A})$ and $25^{\circ} \mathrm{C}(\mathrm{B})$. and - - represent the first, second and summer generations, respectively.

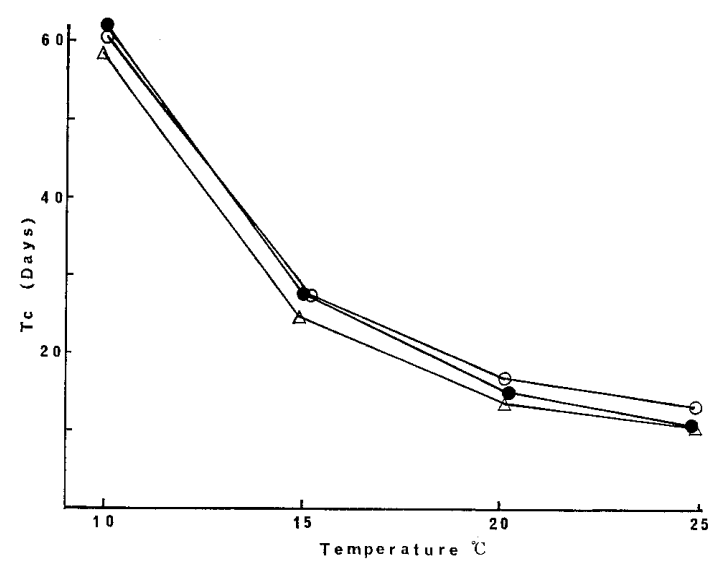

Fig. 7. Relationship between temperature and cohort generation time $\left(T_{\mathrm{c}}\right)$ in Toxoptera citricidus. $\bigcirc, \bigcirc$ and $\Delta$ represent the first, second and the summer generations, respectively.

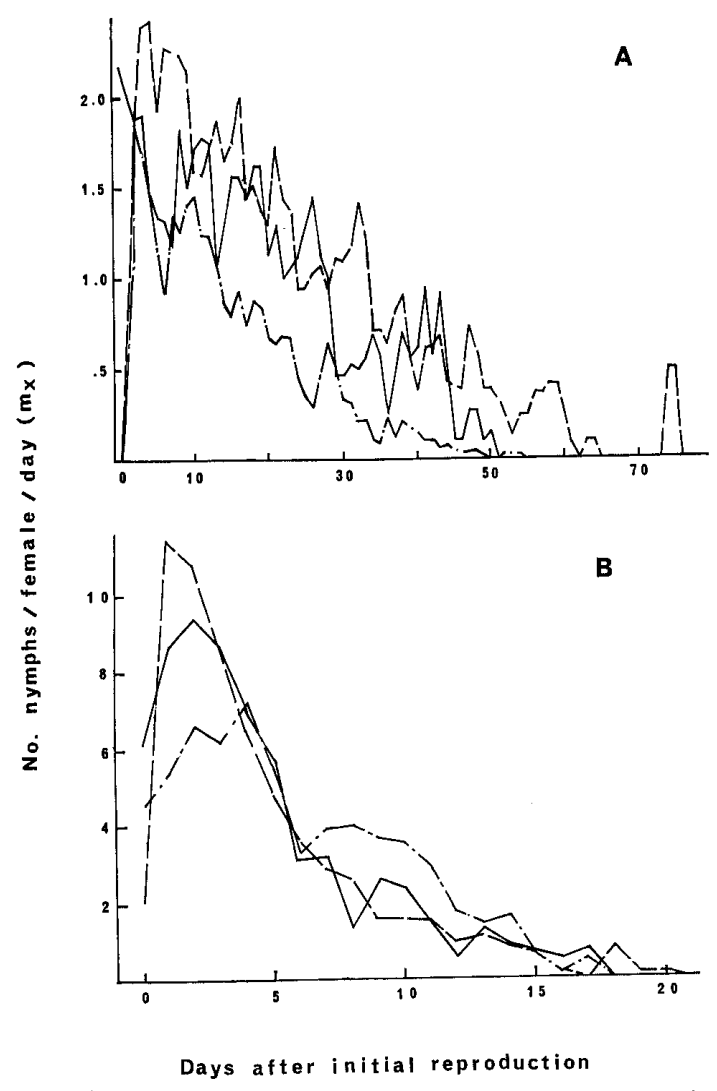

Fig. 6. Age specific fecundity in Aphis citricola at $10^{\circ} \mathrm{C}(\mathrm{A})$ and $25^{\circ} \mathrm{C}(\mathrm{B})$. and --- represent the first, second and summer generations, respectively.

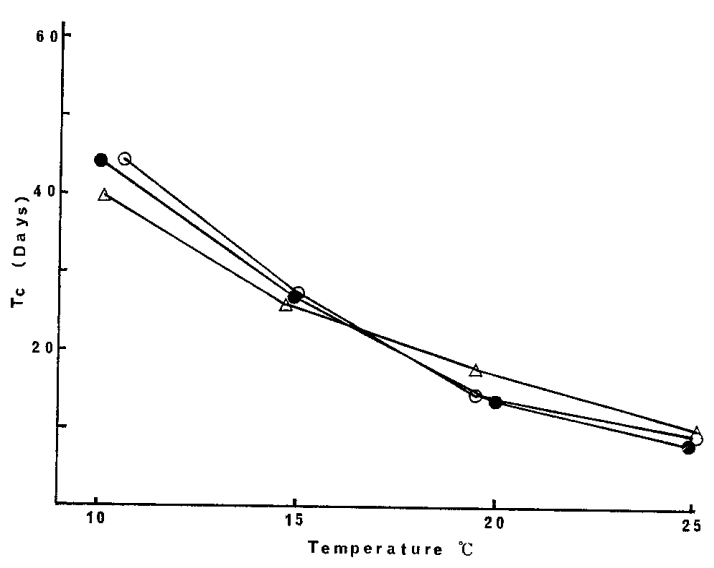

Fig. 8. Relationship between temperature and cohort generation time $\left(T_{\mathrm{c}}\right)$ in Aphis citricola. $\bigcirc$, - and $\triangle$ represent the first, second and the summer generations, respectively. 
As seen in Table 3, the maximum fecundity was lowest at $10^{\circ} \mathrm{C}$ and highest at $20^{\circ} \mathrm{C}$ in all generations in both species. At all temperatures but $10^{\circ} \mathrm{C}$ for T. citricidus, values are considerably lower in the summer generation than in the other generations.

As seen in Table 3 , net reproductive rates $\left(R_{0}\right)$ became maximum between $15^{\circ}$ and $20^{\circ} \mathrm{C}$ except for the first generation of $A$. citricola. Generally speaking, $R_{0}$ values in $T$. citricidus were larger than those in $A$. citricola.

The $m_{x}$ curves at $10^{\circ} \mathrm{C}$ and $25^{\circ} \mathrm{C}$ are shown in Figs. 5 and 6 . In fundatrices, the peak of $m_{x}$ curve came on the first day of their reproductive life and their reproductive period was much shorter than individuals in the subsequent generations at lower temperatures, while at the higher temperature, the peak appeared much later and their reproductive period was never shorter.

As shown in Figs. 7 and 8, cohort generation time $\left(T_{\mathrm{c}}\right)$ became shorter as temperature rose in both species. Similar trends in relationship between temperature and $T_{\mathrm{c}}$ were observed among the generations.

The survival rates at the beginning of larviposition were relatively low in fundatrices, especially when reared at $10^{\circ} \mathrm{C}$ (Table 3 ).

\section{DISCUSSION}

As mentioned, results of the experiments suggest that in both species the second generation individuals can increase more rapidly than the fundatrices. Generation specific ovariole number and fecundity were reported in several aphid species (DIXon and Dharma, 1980; Wellings et al., 1980; Leather and Wellings, 1981). These facts indicate the existence of a generation specific increase rate. The large increasing capacity observed in the second generation is believed to have been brought about by the short maturing time, while the small $r_{\mathrm{c}}$ values observed in the fundatrix generation by the low developmental speed and low survival rate at the immature stage.

The second generation individuals were more fecund than fundatrices in the two citrus aphids dealt with in this paper. A similar result was obtained for Rhopalosiphum padi (L.) (Leather and Dixon, 1981). However in Aphis fabae Scop. (Dixon and Dharma, 1980) fundatrices are more fecund than the second generation individuals. It is thus suggested that difference in fecundity between these generations is dependent on the species, though the reason for this is unknown.

The fundatrices of $A$. citricola developed from the middle of March to the middle of April, while those of $T$. citricidus did not develop until late in March (Komazaki et al., 1979). Meteorological data at this Experimental station shows the mean temperature this season usually rises from about $10^{\circ} \mathrm{C}$ (in the latter half of $\mathrm{March}$ ) to $15^{\circ} \mathrm{C}$ (in the middle of April). The study revealed that at this range of temperature, fundatrices of these two citrus aphids needed more time from birth to maturation than the other generations. The same result was reported for Myzus persicae (Sulz.) by Takaoka (1960). As shown in a model analysis (GAdGil and Bossert, 1970), delayed maturation in fundatrices is closely related to severe environmental conditions, i.e. low temperature and low food availability, to which they may be subjected.

\section{REFERENCES}

Drxon, A. F. G. and T. R. Dharma (1980) Number of ovarioles and fecundity in the black bean aphid, 
Aphis fabae. Ent. Exp. \& Appl. 28: 1-14.

Gadgil, M. and W. H. Bossert (1970) Life historical consequences of natural selection. Am. Nat. 104: 1-24.

Hille Ris Lambers, D. (1966) Polymorphism in Aphididae. Annu. Rev. Entmol. 11: 47-78.

Komazaki, S. (1982) Effects of constant temperatures on population growth of three aphid species, Toxoptera citricidus (KIRKaldy), Aphis citricola van DER GooT and Aphis gossypii Glover (Homoptera: Aphididae) on citrus. Appl. Ent. Zool. 17: 75-81.

Komazaki, S. (1983) Overwintering of the spirea aphid, Aphis citricola van DER Goot (Homoptera: Aphididae) on citrus and spirea plants. Appl. Ent. Zool. 18: 301-307.

Komazaki, S. (1986) The inheritance of egg hatching time of the spirea aphid, Aphis citricola van DER Goot (Homoptera, Aphididae) on the two winter hosts. Kontyu 54: 48-53.

Komazaki, S., Y. SAKagami and R. Korenaga (1979) Overwintering of aphids on citrus trees. Jpn. J. Appl. Ent. Zool. 23: 246-250 (in Japanese with English summary).

Komazaki, S., Y. Sakagami and R. Korenaga (1985) Population dynamics of citrus aphids. I. Attacking species and seasonal and annual population trends. Bull. Fruit Tree Res. Stn. B12: 87-94 (in Japanese with English summary).

Laughlin, R. (1965) Capacity for increase: a useful population statistic. J. Anim. Ecol. 34: 77-91.

Leather, S. R. and A. F. G. Dixon (1981) Growth, survival and reproduction of the bird-cherry aphid, Rhopalosiphum padi, on its primary host. Ann. Appl. Biol. 99: 115-118.

Leather, S. R. and P. W. Wellings (1981) Ovariole number and fecundity in aphids. Ent. Exp. \& Appl. 30: $128-133$.

TAKada, H. (1984) Ovariole number and fecundity in fundatrices of Myzus persicae (Sulzer) (Homoptera: Aphididae). Jpn. J. Appl. Ent. Zool. 28: 250-253 (in Japanese with English summary).

TAKaOKa, I. (1960) Studies on the differentiation of morphological and ecological characters found in the lifecycle of the green peach aphid, Myzus persicae (Sulzer). Bull. Hatano Tobacco Exp. Stn. 48: 1-95 (in Japanese with English summary).

TAYLOR, L. R. (1975) Longevity, fecundity and size; control of reproductive potential in a polymorphic migrant, Aphis fabae Scop. J. Anim. Ecol. 44: 135-163.

Wellings, P. W., S. R. Leather and A. F. G. Dixon (1980) Seasonal variation in reproductive potential: a programmed feature of aphid life cycles. J. Anim. Ecol. 49: 975-985.

Wiktelius, S. and P. A. Chiverton (1985) Ovariole number and fecundity for the two emigrating generations of the bird cherry-oat aphid Rhopalosiphum padi in Sweden. Ecol. Ent. 10: 349-355. 